Check for updates

Cite this: RSC Adv., 2019, 9, 4157

\title{
A facile and scalable process to synthesize flexible lithium ion conductive glass-ceramic fibers
}

\author{
Kun He, ${ }^{a}$ Pu Xie, (D) *b Chengkui Zu, ${ }^{a}$ Yanhang Wang, ${ }^{a}$ Baoying $\mathrm{Li}^{a}{ }^{a}$ Bin Han, ${ }^{a}$ \\ Min Zhi Rong ${ }^{\mathrm{b}}$ and Ming Qiu Zhang (D) ${ }^{\mathrm{b}}$
}

Solid-state electrolytes have emerged as a promising alternative to existing liquid electrolytes for nextgeneration flexible Li metal batteries with enhanced safety and stability. Nevertheless, the brittleness and inferior room temperature conductivity are major obstacles for practical applications. Herein, for the first time, we have fabricated a flexible lithium ion conductive glass-ceramic fiber by using a melt-spun homogeneous NASICON-type structured $\mathrm{Li}_{1.5} \mathrm{Al}_{0.5} \mathrm{Ge}_{1.5}\left(\mathrm{PO}_{4}\right)_{3}$ (LAGP) glass melt and annealed at $825^{\circ} \mathrm{C}$. The annealed samples exhibited a higher lithium ion conductivity than the air-quenched sample due to the presence of a well-crystallized crystal grain in the annealed sample. Meanwhile, the ionic conductivity has shown an inverse relationship with the diameter of annealed LAGP glass-ceramic fibers. The results revealed that the annealed glass-ceramic fiber, with a diameter of $10 \mu \mathrm{m}$, resulted in lithium ion conductivity of $8.8 \times 10^{3} \mathrm{~S} \mathrm{~cm}^{-1}$ at room temperature.

Received 10th October 2018

Accepted 24th January 2019

DOI: $10.1039 / \mathrm{c} 8 \mathrm{ra0} 8401 \mathrm{~g}$

rsc.li/rsc-advances

due to the interaction between electrolyte and Li metal electrode during cycling. ${ }^{17,18}$ Compared to liquid electrolytes, solid electrolytes generally offer better thermal and mechanical stability, wider electrochemical window, non-flammability and electronic insulation. The solid electrolytes can be classified into ceramic electrolytes, polymer solid electrolytes and composite solid electrolytes. ${ }^{16-23}$ Ceramic electrolytes usually have better mechanical and thermal stability over organic (polymer-based) electrolytes. However, ceramics electrolytes exhibit typical high strength and brittle nature of ceramics, inferior room temperature conductivity and energy consuming synthesis process. Various classes of ceramic materials have been investigated, ${ }^{9,12,13}$ such as oxides, sulfides, LIPON-type oxynitrides, LISICON-type materials (Li superionic conductor) and NASICON-type phosphates (Na superionic conductor). The oxides electrolytes either have an exceptionally high conductivity at room temperature or stability by themselves and against Li metal. LIPON suffers from low room temperature ionic conductivity, whereas NASICON-type solid electrolytes demonstrate a reasonably high conductivity but are unstable against $\mathrm{Li}$ metal. LISICON-type electrolytes exhibit low conductivity and poor stability. One should note that the solid electrolytes have a great potential to address the safety issues of Li-ion batteries, but better synthesis methods need to be developed for ceramic electrolytes with different shapes and designs, and enhanced conductivity and stability, i.e., a flexible fiber-like solid electrolyte.

Herein, for the first time, we have explored a simple and

${ }^{a}$ China Building Materials Academy, Beijing 100024, China

${ }^{b}$ Key Laboratory for Polymeric Composite and Functional Materials of Ministry of Education, GD HPPC Lab, School of Chemistry, Sun Yat-sen University, Guangzhou 510275, China.E-mail:275343752@qq.com; cesrmz@mail.sysu.edu.cn; ceszmq@ mail.sysu.edu.cn scalable process to prepare a flexible lithium ion conductive glass-ceramic fiber, which was directly melt-spun from homogeneous glass melts at $1350{ }^{\circ} \mathrm{C}$. One of the NASICON-type 
materials, $\mathrm{Li}_{1.5} \mathrm{Al}_{0.5} \mathrm{Ge}_{1.5}\left(\mathrm{PO}_{4}\right)_{3}$ (LAGP), has been used as an example to demonstrate the formation of fiber-like glassceramic electrolyte due to the distinct advantages of NASICON-type ceramic materials, such as high ionic conductivity, chemical stability and wide electrochemical voltage window. After annealing LAGP glass fibers at $825^{\circ} \mathrm{C}$ for $6 \mathrm{~h}$, the glass-ceramic fibers, with different diameters, exhibited superior Li ion conductivity, which increased with decreasing diameter. The LAGP glass-ceramic fibers can be promising flexible lithium ion conductive electrolytes for flexible energystorage applications.

\section{Experimental}

Lithium carbonate $\left(\mathrm{Li}_{2} \mathrm{CO}_{3}\right)(99.9 \%)$, aluminium oxide $\left(\mathrm{Al}_{2} \mathrm{O}_{3}\right)$ (99.9\%), germanium oxide $\left(\mathrm{GeO}_{2}\right)(99.9 \%)$ and ammonium phosphate monobasic $\left(\mathrm{NH}_{4} \mathrm{H}_{2} \mathrm{PO}_{4}\right)(99.9 \%)$ were purchased from Sigma-Aldrich and used without further purification. Stoichiometric amounts of $\mathrm{Li}_{2} \mathrm{CO}_{3}, \mathrm{Al}_{2} \mathrm{O}_{3}, \mathrm{GeO}_{2}$ and $\mathrm{NH}_{4} \mathrm{H}_{2} \mathrm{PO}_{4}$ were used as the starting materials to prepare LAGP by conventional solid solution method. $10 \mathrm{wt} \%$ excess lithium carbonate was added to compensate for the loss of lithium during the melting processing. The powders were weighed, mixed and milled in a high energy ball milling machine for $60 \mathrm{~min}$. Then, the mixture was transferred to an electric furnace and heated up to $700{ }^{\circ} \mathrm{C}$ in an alumina crucible for $2 \mathrm{~h}$ to remove decomposed ammonia, carbon dioxide and water vapors from the mixture. The mixed powder was melted at $1350{ }^{\circ} \mathrm{C}$ for $2 \mathrm{~h}$ to obtain a homogeneous glass melt. Finally, the glass fibers with different diameters were drawn from the glass melt at $1100{ }^{\circ} \mathrm{C}$. To obtain glass-ceramic fibers, parts of the glass fibers were crystallized at $825^{\circ} \mathrm{C}$ for $6 \mathrm{~h}$ with a heating rate of $5{ }^{\circ} \mathrm{C} \min ^{-1}$ (Scheme 1).

The morphology of LAGP glass-ceramic fibers was observed by field emission scanning electron microscopy (FESEM, Hitachi S-4800) and the crystal structure was identified by X-ray diffraction (XRD) measurements (Bruker D8 Advance), equipped with $\mathrm{Cu} \mathrm{K} \alpha$ radiations $(\lambda=1.54178)$, in the $2 \theta$ range of $10-$ $80^{\circ}$. The electrochemical measurements were carried out by using a CHI 760E electrochemical workstation. To measure the ionic conductivity, the symmetric Au|LAGP fiber electrolyte|Au cells were prepared, where Au layers were coated on two joint surfaces of the LAGP fiber via two times spray-gold treatment and acted as the blocking electrode. The sputtering was carried out for $300 \mathrm{~s}$ under the sputtering current of $15 \mathrm{~mA}$ and an $\mathrm{Ar}$

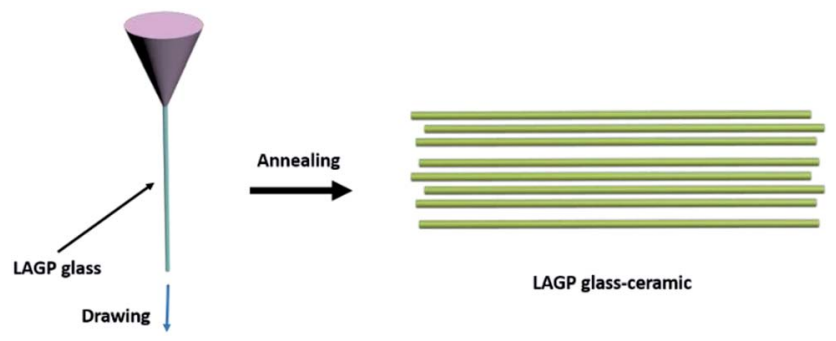

Scheme 1 Schematic illustration of the LAGP glass-ceramic fiber synthesis. pressure of $\sim 0.02$ mbar. Subsequently, the LAGP fiber electrolyte with Au layer was adhered to copper sheet fixture by using silver glue. In order to separate grain and grain boundary contributions, the electrochemical impedance spectroscopy (EIS) data were fitted based on an equivalent circuit, consisting of a resistance $\left(R_{\mathrm{g}}\right)$ and a capacitance $\left(C_{\mathrm{g}}\right)$, corresponding to the grain contribution, in series with a parallel combination of a resistance $\left(R_{\mathrm{gb}}\right)$ and a constant-phase element $\left(\mathrm{CPE}_{\mathrm{gb}}\right)$, corresponding to the grain boundary contribution, and with a constant-phase element $\left(\mathrm{CPE}_{\mathrm{e}}\right)$, which represents the electrode polarization in the low frequency region. Then, the ionic conductivity $\left(\sigma, \mathrm{S} \mathrm{cm}^{-1}\right)$ was calculated from the $\sigma=L / R S$, where $R(\Omega)$ refers to the total resistance of the $R_{\mathrm{g}}$ and $R_{\mathrm{gb}}$ measured by EIS, with an AC amplitude of $10 \mathrm{mV}$ from $10^{6} \mathrm{~Hz}$ to $10^{-1} \mathrm{~Hz}, L$ (cm) corresponds to the length of electrolyte fiber between two fixture point and $S\left(\mathrm{~cm}^{2}\right)$ denotes the cross-section area of the fiber.

\section{Results and discussion}

In order to overcome the brittleness of the ceramic electrolytes, a novel glass-ceramic fiber has been fabricated by using a combination of melt spun and annealing method. First, the stoichiometric amounts of $\mathrm{Li}_{2} \mathrm{CO}_{3}, \mathrm{Al}_{2} \mathrm{O}_{3}, \mathrm{GeO}_{2}$ and $\mathrm{NH}_{4} \mathrm{H}_{2} \mathrm{PO}_{4}$ were used as starting materials to prepare LAGP by conventional solid solution method. Then, the mixture was transferred to an electric furnace and heated up to $1350{ }^{\circ} \mathrm{C}$ for $2 \mathrm{~h}$ in an alumina crucible to obtain a homogeneous glass melt, which removed the decomposed ammonia, carbon dioxide and water vapors from the starting materials. The glass fibers, with different diameters, were drawn from the glass melt at $1100{ }^{\circ} \mathrm{C}$ by changing the drawing speed. Flexible lithium ion conductive glass-ceramic fibers have been obtained after annealing at $825{ }^{\circ} \mathrm{C}$ for $6 \mathrm{~h}$. The as-spun glass fibers exhibited a smooth surface with a diameter of $\sim 10 \mu \mathrm{m}$ (Fig. 1a). After annealing, the glass-ceramic fibers shrank and demonstrated a rough surface with kinky morphology, as shown in Fig. 1b-d. The SEM images of the fractured surface of LAGP glass fiber (Fig. 1e), which was air-quenched at room temperature, and LAGP glass-ceramic fibers (Fig. 1f-h), which were annealed at $825{ }^{\circ} \mathrm{C}$ for $6 \mathrm{~h}$, are presented in Fig. 1. A considerable difference in the fracture morphology of the samples annealed at $825{ }^{\circ} \mathrm{C}$ for $6 \mathrm{~h}$ and airquenched has been observed in SEM images. The high magnification SEM images revealed that the fibers had been formed through the merging of LAGP particles. Moreover, the fracture morphology of the glass fibers, with different diameters, has shown a significant difference under the same annealing conditions $\left(825{ }^{\circ} \mathrm{C}\right.$ for $6 \mathrm{~h}$ ). However, most of the glassy phase remained intact with the formation of crystalline grains, which indicates that annealing at $825{ }^{\circ} \mathrm{C}$ for $6 \mathrm{~h}$ is sufficient for NASICON-type phase growth. Fig. 1e presents a smooth crosssectional morphology without any obvious grains for the airquenched sample, which can be ascribed to the enhanced grain coarsening at a higher crystallization temperature of $825{ }^{\circ} \mathrm{C}$ for LAGP. In addition, Fig. 1 shows that LAGP glassceramic fibers, with different diameters, can be obtained by changing the drawing speed. The average diameter of the LAGP 

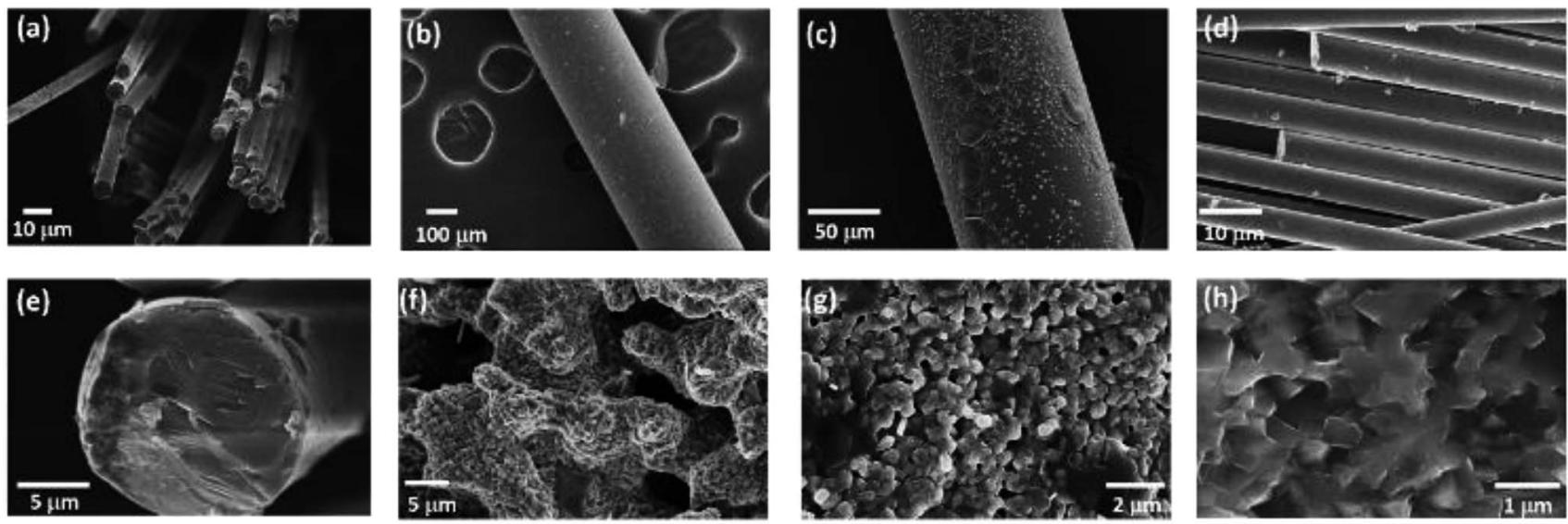

Fig. 1 SEM images of LAGP glass fibers ( $a$ and e) and glass-ceramic fibers ( $b-d, f-h)$ with different diameters, (b and f) glass-ceramic fibers-300 (diameter of $300 \mu \mathrm{m}$ ), (c and g) glass-ceramic fibers-100 (diameter of $100 \mu \mathrm{m}$ ) and ( $\mathrm{d}$ and h) glass-ceramic fibers-10 (diameter of $10 \mu \mathrm{m}$ ).

glass-ceramic fibers decreased with increasing drawing rate and the diameter distribution of fibers became narrow. Moreover, the smaller diameter of the LAGP glass fibers enhanced the crystallization and resulted in a pore-free structure (Fig. 1h).

The cross-sectional SEM images of the fractured pellets were observed to better understand the influence of process conditions on microstructural features. The pellets derived from conventional sol-gel and electrospinning possess more pores and voids than the pellets derived from the melt-spun fibers. ${ }^{16,19,23-29}$ In general, the particles sintering involves neck formation, mass transport and pore closure, with the major driving force being the reduction of total surface energy. Nanoparticles exhibit a large surface-to-volume ratio with high surface energy, which implies that the sintering of nanoparticles should yield high-density pellets due to the presence of a large driving force. However, the pores and defects of the crystalline phase continued to disappear when the diameter of the fibers was decreased from 300 to $10 \mu \mathrm{m}$. One should note that the smaller diameter enhanced the crystallization and reduced the shrinkage of fibers. Meanwhile, the tetragonal NASICON-type crystal structure has been obtained after annealing at $825{ }^{\circ} \mathrm{C}$ for 6 hours. The results revealed that the annealed LAGP glass ceramic fibers have a polycrystalline structure, with a diameter of $<200 \mathrm{~nm}$ and a grain size of 50$200 \mathrm{~nm}$. Moreover, Fig. 2 indicates that the glass-ceramic fibers posses remarkable flexibility.
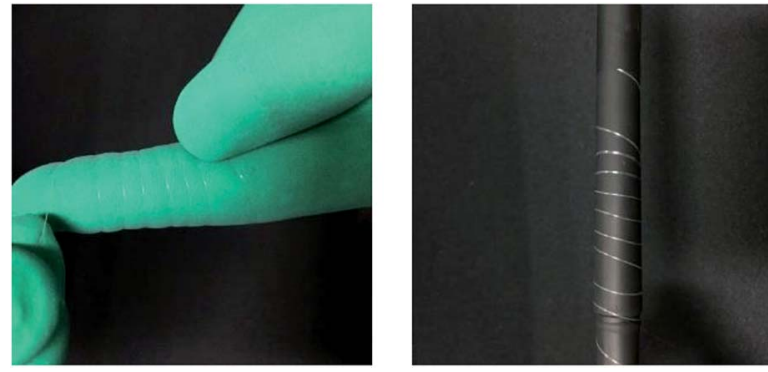

Fig. 2 Optical images of glass-ceramic fibers sample $(10 \mu \mathrm{m})$ convolving forefinger (left) and pencil (right).
Energy dispersive spectroscopy (EDS) was used to qualitatively assess the chemical composition of LAGP (Fig. 3). Li was omitted because it is too subtle for EDS to detect. The EDS maps exhibited the presence and homogenous distribution of oxygen $(\mathrm{O})$, phosphorus (P), aluminum ( $\mathrm{Al}$ ) and germanium (Ge) in asprepared fibers, which implies that side reactions products (non-conducting $\mathrm{Li}_{3} \mathrm{PO}_{4}$ ) did not form during sintering and annealing processes. Table 1 summarizes the chemical composition of the as-prepared LAGP, which is almost consistent with the starting stoichiometric ratio.

The ionic conductivity of fibers strongly depends on the crystal structure and tunnel size for Li-ion migration. The X-ray diffraction (XRD) patterns present broad diffraction peaks at $2 \theta$ $=15.0^{\circ}, 21.2^{\circ}, 21.4^{\circ}, 25.2^{\circ}, 30.2^{\circ}, 33.3^{\circ}, 33.7^{\circ}, 37.7^{\circ}, 45.0^{\circ}$, $48.8^{\circ}, 51.7^{\circ}, 56.4^{\circ}$, and $59.1^{\circ}$ for after annealing at $825^{\circ} \mathrm{C}$, which correspond to (012), (104), (110), (113), (024), (211), (116), (214), (208), (218), (042), (137) and (410) diffraction planes of LAGP (JCPDS card 80-1924) (Fig. 4). ${ }^{23}$ However, the intensity of the peaks decreased with increasing diameter, which indicates that the larger diameter resulted in inferior crystallinity. The sharp and high-intensity XRD peaks were observed after annealing at $825{ }^{\circ} \mathrm{C}$, which confirms the formation of a highly crystalline structure. Moreover, the XRD pattern of the fibers, annealed at $825^{\circ} \mathrm{C}$, did not show any impurity peaks and all peaks can be indexed to the standard hexagonal structure of LAGP. However, the air-quenched sample did not exhibit any distinct diffraction
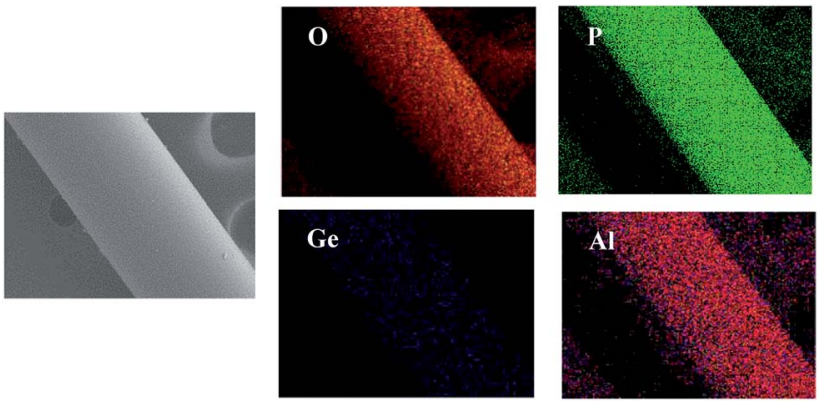

Fig. 3 The SEM image and corresponding EDS maps of the glassceramic fibers sample $(300 \mu \mathrm{m})$. 
Table 1 The EDS analysis of the as-prepared LAGP glass-ceramic fibers

\begin{tabular}{llllll}
\hline Element & $\mathrm{P}$ & $\mathrm{Ge}$ & $\mathrm{O}$ & $\mathrm{Al}$ & Total \\
\hline LAGP theoretical (at\%) & 17.64 & 8.82 & 70.59 & 2.95 & 100 \\
LAGP experimental (at\%) & 17.57 & 8.40 & 70.93 & 3.1 & 100
\end{tabular}

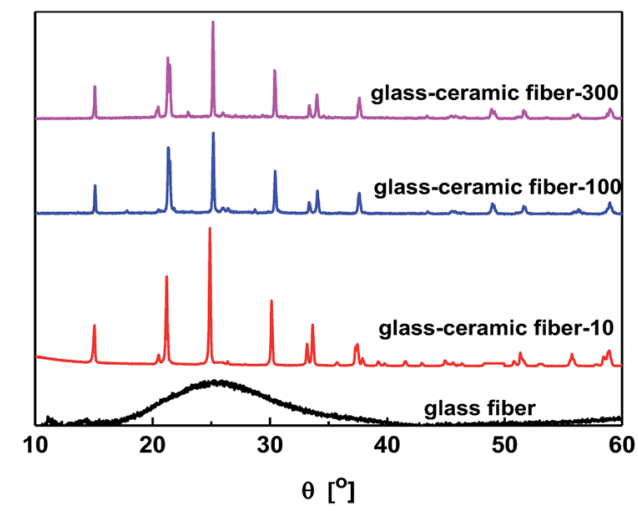

Fig. 4 The XRD patterns of the as-prepared LAGP samples, which were annealed at $825^{\circ} \mathrm{C}$ and air-quenched.

peak, which suggests that the air-quenched sample has an amorphous structure, which is not desirable for Li-ion conduction. Moreover, these results are consistent with the SEM images.

To further understand the $\mathrm{Li}^{+}$transport properties of the LAGP fibers, the electrochemical impedance spectroscopy (EIS) was carried out at room temperature. The variation in Nyquist plots of LAGP glass-ceramic fiber with respect to the diameter of the fibers is illustrated in Fig. 5. One should note that all samples have exhibited one semicircle in the high-frequency region. For an ionic conductor with high ionic conductivity, the semicircle in the high-frequency range corresponds to the bulk impedance $\left(R_{\mathrm{b}}\right)$ of the blocking electrodes. The large bulk impedance of the air-quenched sample can be ascribed to the inferior crystallinity and absence of crystal grains for $\mathrm{Li}^{+}$ transport, which is consistent with XRD measurements (Fig. 4). The presence of a sloping line in the low-frequency region indicates the ionic nature of the NASICON-type electrolyte in a blocking electrode. The total bulk impedance $\left(R_{\mathrm{b}}\right)$ and crystalline grain bulk impedance $\left(R_{\mathrm{gb}}\right)$ of a sample can be obtained
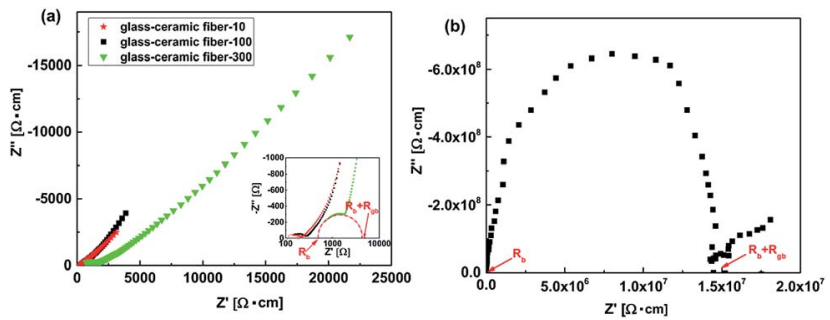

Fig. 5 The Nyquist plots of the as-prepared LAGP samples after different processes: (a) annealing at $825^{\circ} \mathrm{C}$ and (b) air-quenching. Glass-ceramic fiber-10, glass-ceramic fiber-100, glass-ceramic fiber300 refers to the diameter of $10 \mu \mathrm{m}, 100 \mu \mathrm{m}$ and $300 \mu \mathrm{m}$, respectively. from the left intercept of the semicircle with the real axis. The glass-ceramic fiber-10, glass-ceramic fiber-100 and glassceramic fiber-300 have shown a total conductivity of $4.0 \times$ $10^{-3} \mathrm{~S} \mathrm{~cm}^{-1}, 1.7 \times 10^{-3} \mathrm{~S} \mathrm{~cm}^{-1}$ and $1.6 \times 10^{-4} \mathrm{~S} \mathrm{~cm}^{-1}$, respectively, whereas the air-quenched sample has exhibited the total conductivity of $6.7 \times 10^{-8} \mathrm{~S} \mathrm{~cm}^{-1}$. In summary, the airquenched sample has shown the highest impedance due to the absence of crystalline grains, whereas the samples annealed at $825{ }^{\circ} \mathrm{C}$ have shown the lowest impedance. Moreover, the impedance of the glass-ceramic fibers has exhibited a direct relationship with the fiber diameter due to the presence of voids and defects in fibers with a larger diameter. Hence, the glassceramic fibers, with a smaller diameter, are desirable to achieve high ionic conductivity. These results are consistent with XRD and SEM observations.

\section{Conclusions}

In summary, we have demonstrated a melt-spun method to synthesize glass ceramic fibers for the first time. The pores and defects of the crystalline phase have been significantly reduced compared to conventional solid state and electrospinning methods. In addition, we have compared the crystal structure, morphology and conductivity of the annealed and air quenched glass-ceramic LAGP fibers. The tetragonal NASICON-type crystal structure has been obtained after annealing at $825{ }^{\circ} \mathrm{C}$ for 6 hours. The results revealed that the annealed LAGP glass ceramic fibers are polycrystalline, with a diameter of $<200 \mathrm{~nm}$ and a grain size of $50-200 \mathrm{~nm}$. The dense and void-free pellets were obtained after sintering, which have exhibited an improved ionic conductivity of $10^{-3} \mathrm{~S} \mathrm{~cm}^{-1}$ at room temperature. One should note that the proposed method resulted in superior properties than conventional electrospinning and solgel processes. It is expected that the ionic conductivity of the fibers can be further enhanced by tuning synthesis parameters, which result in a crystalline phase with a lower number of pores and defects. These results highlight the potential of utilizing the melt-spun method to improve the ionic conductivity of derivative inorganic solid electrolytes.

\section{Conflicts of interest}

The authors declare no conflict of interest.

\section{Acknowledgements}

The authors are grateful for the financial support by the National Nature Science Foundation of China (Grant: 51333008) and Young Teacher Training Program of Sun Yat-sen University (Grant: 17lgpy86) and the Natural Science Foundation of Guangdong Province of China (Grant: 2018A0303130204).

\section{Notes and references}

1 Y. He, B. Matthews, J. Wang, L. Song, X. Wang and G. Wu, J. Mater. Chem. A, 2018, 6, 735-753. 
2 Y. Liu, G. Zhou, K. Liu and Y. Cui, Acc. Chem. Res., 2017, 50, 2895-2905.

3 W. Liu, M. Song, B. Kong and Y. Cui, Adv. Mater., 2017, 29, 1603436.

4 X. Cheng, R. Zhang, C. Zhao and Q. Zhang, Chem. Rev., 2017, 117, 10403-10473.

5 K. K. Fu, Y. Gong, J. Dai, A. Gong, X. Han, Y. Yao, C. Wang, Y. Wang, Y. Chen, C. Yan, Y. Li, E. D. Wachsman and L. Hu, PNAS, 2016, 113, 7094-7099.

6 W. Zeng, L. Shu, Q. Li, S. Chen, F. Wang and X. Tao, Adv. Mater., 2014, 26, 5310-5336.

7 D. Li, L. Chen, T. Wang and L. Fan, ACS Appl. Mater. Interfaces, 2018, 10, 7069-7078.

8 P. Xie, M. Z. Rong and M. Q. Zhang, Angew. Chem., Int. Ed., 2016, 55, 1805-1809.

9 Y. Liang, W. Zhang, D. Wu, Q. Ni and M. Q. Zhang, Adv. Mater. Interfaces, 2018, 5, 1800430.

10 H. Xiao, P. Xie, S. J. Qiu, M. Z. Rong and M. Q. Zhang, Carbon, 2018, 139, 648-655.

11 A. Zhu, P. Xie, J. Nong, M. Z. Rong, M. Q. Zhang and Y. M. Guo, Nanotechnology, 2018, 29, 465402.

12 M. Zhu, J. Nong, P. Xie, A. Zhu, M. Z. Rong and M. Q. Zhang, Electrochim. Acta, 2019, 295, 624-631.

13 J. Nong, M. Zhu, K. He, P. Xie, A. S. Zhu, M. Z. Rong and M. Q. Zhang, J. Energy Chem., 2019, 34, 220-226.

14 J. Nong, P. Xie, A. S. Zhu, M. Z. Rong and M. Q. Zhang, Carbon, 2019, 142, 177-189.

15 J. Y. Chen, P. Xie and Z. P. Zhang, Chem. Eng. J., 2019, 361, 615-624.
16 K. H. Park, Q. Bai, D. H. Kim, D. Y. Oh, Y. Zhu, Y. Mo and Y. S. Jung, Adv. Energy Mater., 2018, 8, 1800035.

17 H. Xie, C. Yang, K. K. Fu, Y. Yao, F. Jiang, E. Hitz, B. Liu, S. Wang and L. Hu, Adv. Energy Mater., 2018, 8, 1703474.

18 M. Wang, X. Chen, H. Wang, H. Wu, X. Jin and C. Huang, J. Mater. Chem. A, 2017, 5, 311-318.

19 Q. Guo, Y. Han, H. Wang, S. Xiong, Y. Li, S. Liu and K. Xie, ACS Appl. Mater. Interfaces, 2017, 9, 41837.

20 Z. D. Gordon, T. Yang, G. B. Gomes Morgado and C. K. Chan, ACS Sustainable Chem. Eng., 2016, 4, 6391-6398.

21 W. Liu, S. W. Lee, D. Lin, F. Shi, S. Wang, A. D. Sendek and Y. Cui, Nat. Energy, 2017, 2, 17035.

22 W. Liu, N. Liu, J. Sun, P. Hsu, Y. Li, H. Lee and Y. Cui, Nano Lett., 2015, 15, 2740-2745.

23 J. Evans, C. A. Vincent and P. G. Bruce, Polymer, 1987, 28, 2324-2328.

24 W. Zeng, L. Shu, Q. Li, S. Chen, F. Wang and X. Tao, Adv. Mater., 2014, 26, 5310-5336.

25 M. Tatsumisago and A. Hayashi, Solid State Ionics, 2012, 225, 342-345.

26 X. Xu, Z. Wen, X. Wu, X. Yang and Z. Gu, J. Am. Ceram. Soc., 2007, 90, 2802-2806.

27 L. Buannic, M. Naviroj, S. M. Miller, J. Zagorski, K. T. Faber and A. Llordés, J. Am. Ceram. Soc., 2018, 10, 1-9.

28 X. Zhang, T. Liu, S. Zhang, X. Huang, B. Xu, Y. Lin, B. Xu, L. Li, C. Nan and Y. Shen, J. Am. Chem. Soc., 2017, 139, 13779-13785.

29 G. Lancel, P. Stevens, G. Toussaint, M. Maréchal, N. Krins, D. Bregiroux and C. Laberty-Robert, Langmuir, 2017, 33, 9288-9297. 